\title{
Socially oriented non-profit organizations in the region in the processes of creating the conditions for harmonious development of the individual: the financial aspect
}

\author{
Elena Dvoryadkina*,Dina Prostova, and Natalya Istomina \\ Ural State University of Economics, 620144 Ekaterinburg, Russia
}

\begin{abstract}
In this study the authors examine how socially oriented nonprofit organizations are involved in the processes of creating conditions for harmonious personal development in contemporary realities. The financial aspect, which is directly linked to the increase in funding from public funds and organizations, contributes to this degree. As human life consists of three main components, such as physical needs, social needs and spiritual needs, we consider it necessary to take a closer look at social needs, which include the need of culture, education, leisure and tourism, which can be provided by non-profit organizations.
\end{abstract}

\section{Introduction}

The activity and influence of non-profit organizations in almost every country in the world has grown exponentially in recent decades. "Non-profit organizations, as full-fledged economic actors, are becoming a real economic factor influencing the creation of gross value added and, consequently, the economic growth of the region"[1]. The rise of nonprofit organizations is partly a consequence [8] of the "bottom up" growth in social activism and civic engagement. However, it is also a consequence of targeted top-down development policies by governments, which view non-profit organizations as tools for achieving their aims.

Non-profit organizations are organized for public or mutual benefit, except for profit for the owners or investors [2]. The characteristic of non-profit distribution means that contrary to popular belief - non-profit organizations can make a profit but cannot distribute it to owners or directors [6,7]. Profits should be used to support the activities of the organization [3]. "It should be noted that it is very important for a non-profit organization to be profitable in order to maintain activities consistent with its mission. Profits from operations or donations are invested in capital costs, such as premises and equipment, or income-generating assets to provide funding for future operations. Non-profit organizations enhance the efficiency of the social service delivery system" [4].

The term "socially oriented non-profit organizations" was introduced in the Russian Federation by Federal Act No. 40 on $5^{\text {th }}$ of April 2010 on Amendments to Certain

\footnotetext{
*Corresponding author: elena.dvoryadkina@yandex.ru
} 
Legislative Acts of the Russian Federation concerning support for socially oriented nonprofit organizations. The concept of "socially oriented non-profit organizations" is analogous to the term "public benefit organizations" (also known as public benefit or charitable organizations) used in the legislation of many countries.

Since 2008 Russia has implemented programs to support SONPOs, including presidential and other federal grants, which are allocated on a competitive basis. SONPOs received tax breaks and subsidized positions. Regional bodies have been given incentive funds to promote cooperation with NPOs. Non-profit organizations are allowed to compete for public contracts for social services.

The region's socially oriented non-profit organizations are actively involved in the process of creating the conditions for the harmonious development of the individual. A harmonious personality refers to the balance between a person's outer and inner worlds. The harmonious developments of the individual's facets include the physical, intellectual, emotional, spiritual, moral and aesthetic [9]. Socially oriented non-profit organizations are a direct provider of social services in a shorter time and at the lowest financial cost, SONPOs carry out their activities in culture, education, health, historic preservation, developing leisure activities and other socially important economic activities.

\section{Materials and Methods}

This research is based on a conceptual approach to the study of socially oriented non-profit organizations, which is grounded in the basic assumptions of regional socio-economic theory, the regional governance paradigm and the theory of the non-profit sector. In the framework of this research, theoretical and empirical research methods were used, in particular the method of analysis and synthesis, the method of analogy, and a systematic analysis of the dynamics of state support grants to non-profit organizations was carried out. The information base for the study included legal and regulatory documents, Rosstat data, regional statistics materials, as well as publications in scientific periodicals on the topic of research (Russian and international researchers).

\section{Results and Discussion}

The Federal Law about Non-Profit Organizations sets out a list of activities that allow a non-profit organization to be given the status of a socially oriented organization. They include various activities aimed at solving social problems and developing civil society in the Russian Federation. The implementation of SONPO activities in the spheres of education, culture, health, historical memory, developmental leisure and other activities has a positive impact on the creation of conditions for the harmonious development of the individual in the region.

In order to address social problems and develop civil society, the state established the Presidential Grants Fund (hereinafter referred to as the PGF). The PGF is a social institution that has great potential to shape social development trends. The Foundation has been the sole operator of the Russian President's grants for the development of civil society since 3rd April 2017. The system of state grant support for non-profit organizations has been in use since 2006. The award for the winners is allocated as material support to the SONPOs to address various socio-economic problems of the state. It should be noted that aid is not given for activities that the organization is already engaged in. Consider grant funding for SONPOs using the Sverdlovsk region as an example.

Within the first, second and special PGF 2020 competitions, 133 projects $(21.5 \%)$ submitted by 123 organizations in the Sverdlovsk region were recognized as winners. At 
the same time, 10 organizations received support for their projects in two PGF 2020 competitions. The total amount of grants allocated to the winning projects was RUB 290,845,313.9.

Table 1. Grants won by NPOs in the Sverdlovsk region.

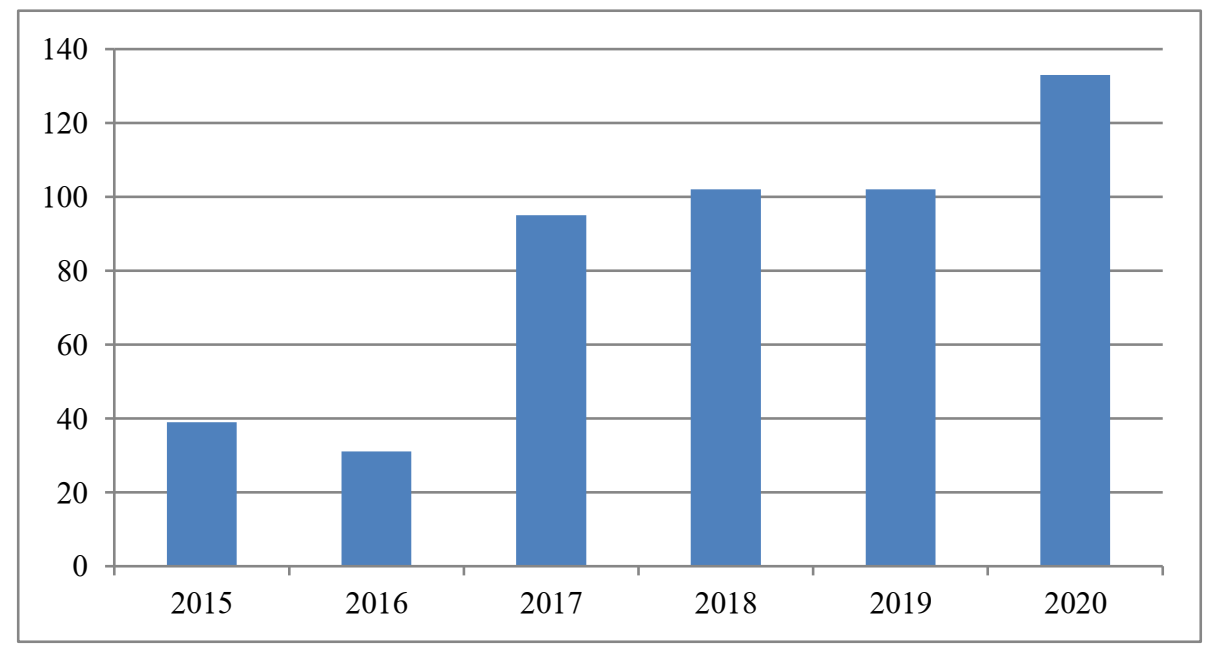

According to Table 1, the amount of grants won by NPOs to implement socially significant projects is steadily increasing in the Sverdlovsk Region. The most funded area during the PGF 2020 competitions, apart from the results of the "PGF Special Competition", is "Identifying and supporting young talents in culture and the arts".

This is a special contest of the Presidential Grants Foundation. The competition distributes funds allocated from the Presidential Reserve Fund of the Russian Federation to support SONPOs involved in combating the spread of coronavirus infection and its consequences. The competition received 3,868 initiatives from 83 regions. It is worth noting that 555 organizations submitted an application to the PGF for the first time.

The special competition has a grant fund of 2 billion rubles. There are 91 projects from the Sverdlovsk region submitted to the PGF for the special 2020 competition, which represents $2.3 \%$ of the total number of applications submitted. Among the projects submitted, 18 were supported, which amounted to $2 \%$, for a total of $31,162,742$ rubles $(0.3 \%$ of the total number of allocated funds for projects in Russia).

Projects submitted by organizations in the Sverdlovsk region, during the 3 PGF 2020 competitions, by grant category:

- Identifying and supporting young talents in culture and the arts. Number of projects submitted - 7, of which 3 (49\%) were supported for a total amount of RUB 58,204,238.

- Support of projects in the field of culture and art. Numbers of submitted projects -62 , 15 of them $(24.2 \%)$ were supported for a total amount of 31,338,169.06 rubles.

- Support of projects in the field of science, education, and enlightenment. Numbers of submitted projects $-70,11$ of them $(15.8 \%)$ were supported for the total amount of 15,387,726 RUB [5].

It should be noted that a broad package of regional support measures (financial, property, information and advisory support) has been adopted and implemented for Sverdlovsk Region's SONPOs. In addition, NPOs in the Sverdlovsk region have traditionally received a solid amount of financial support from the PGFs. At the end of this year's first competition, 53 NPOs in the Sverdlovsk Region received grants total 159.5 million rubles. Given that the Sverdlovsk region became a participant in the PGF co- 
financing program in 2021 (the Sverdlovsk region has approved an application for 25 million rubles), the same amount of funding will be allocated from the regional budget. The Ministry of Social Policy of the Sverdlovsk Region organizes competitions for grants to non-profit organizations as part of the co-financing program.

It should also be noted that on $27^{\text {th }}$ of February 2021, the Russian government published the rules for subsidizing soft loans under the Payroll Fund 3.0 program. The program provides concessional loans at an annual interest rate of 3\%. For the first six months, there are no principal or interest payments for the borrower. It is necessary to repay the loan in equal monthly instalments, plus interest during the next six months. The amount of the loan is based on the minimum wage (12,792 rubles) per employee for 12 months. However, the maximum loan amount may not exceed 500 million rubles.

Among the participants of the program are SONPOs, which are included in the registers of the Ministry of Economic Development of Russia, which are formed in accordance with the regulations of the Government of the Russian Federation from 23.06.2020 № 906 and from 11.06.2020 № 847. One of the prerequisites for obtaining a preferential loan at 3\% per annum is that the borrower must be a participant in the Payroll Fund 2.0 program.

The borrower may only conclude a loan agreement with one credit institution (bank). The loan can be taken out between $9^{\text {th }}$ of March and $1^{\text {st }}$ of July 2021 . According to the Urals Main Directorate of the Bank of Russia, Sverdlovsk Region's SONPOs were approved for loans totaling RUB 96 million under the Payroll Fund 2.0 program in 2020.

\section{Conclusion}

Thus, as it is shown by the dynamics (Table 1), each year the PGF competitions attract more and more SONPOs, and the amount of funds allocated to socially important projects is also increasing year by year. In addition to the PGFs, due to the increased popularity of support to non-profit sector organizations, offers of and opportunities for funding come from a multitude of foundations and organizations, both at federal and local, regional level. NPO support activities are a priority in the implementation of government programs. It is due to the fact that NPOs have proven to be positively capable of covering quite a large layer of activities that cannot be covered by public authorities and state organizations. In this regard, it is more appropriate to fund the activities of NPOs than to launch problem areas that exist in the society.

\section{References}

1. E.B Dvoryadkina, D.M. Prostova, Journal of New Economy, 20, 4 (2019)

2. L. Salamon, America's Nonprofit Sector: A Primer. New York: The Foundation Center (1999)

3. H.K. Anheier, Nonprofit Organizations. New York, Oxon: Routledge (2014)

4. E. Dvoryadkina, D. Prostova, Mechanisms of the sustainable development of nonprofit organizations in the region. E3S Web of Conferences 208, 03023 (2020)

5. Analytical report. Participation of NPOs of the Sverdlovsk Region in competitions Presidential Grants Fund (2020) http://www.opso66.ru/

6. F. Adro, C.I. Fernandes, P.M. Veiga, S. Kraus, International Entrepreneurship and Management Journal, 4 (2021)

7. F. Rebetak, V. Bartosova, SHS Web of Conferences, 74, 05020 (2020)

8. F. Rebetak, V. Bartosova, SHS Web of Conferences, 91, 01027 (2021) 
9. H. Komiyama, Procedia Social and Behavioral Sciences, 41 (2010) 